\title{
Routine circumcision: the opposing view
}

A key mission of our journal is to challenge readers with new concepts and provide new ideas and insights. To accomplish this mission, we have started this new section - Point / Counterpoint. This regular feature will highlight the most important debates in urology. The purpose of the section is to encourage vigorous and informed discussion on controversial issues in urology through the presentation of diverse opinions. We aim for a dispassionate discussion of controversies, recognizing that strong passions may exist in support of some positions.

\section{Andrew E. MacNeily, MD, FRCSC, FAAP}

or millennia, routine newborn male circumcision has been endorsed for a variety of purported benefits. Over the ages, claimed advantages have included the formation of a covenant with god, the enhancement of sexual pleasure, the reduction of sexual pleasure, and a cure for bedwetting, syphilis, penile cancer, mental illness and masturbation. ${ }^{1}$ In more modern times, some advocates of circumcision have equated the procedure to a form of vaccination. ${ }^{2}$ Circumcision is thus depicted as protective against future problems of the foreskin such as phimosis and recurrent balanitis as well as neonatal urinary infection (UTI), cervical carcinoma and HIV/AIDS. Do these potential advantages justify routine circumcision of healthy newborn males on a widespread scale? Should public policy dictate that health care resources be redirected to this procedure when all but 1 province in Canada has delisted newborn circumcision from the schedule of insured services? Let's look at the evidence.

\section{Prevention of urinary tract infection}

It is well established from epidemiological studies first carried out by Wiswell and colleagues that the incidence of febrile UTI in otherwise anatomically normal males in the first year of life is lower in circumcised, compared with intact, males. ${ }^{3}$ The exact risk reduction varies somewhere between 4 -fold and 12 -fold depending on the study one chooses to quote. However, the actual incidence of UTI in the first year of life is low. Even a 10 -fold reduction in infection rates equates to changing the incidence of UTI from 1 in 100 to 1 in 1000 male babies. It has been calculated that the rate of UTI among infant boys with foreskins must equal or exceed $29 \%$ for neonatal circumcision to be cost effective. ${ }^{4}$ Conversely, for neonatal circumcision to be costneutral, each patient hospitalized for UTI would need to cost $\$ 229564 !^{5}$ In 2004, it is estimated that approximately $1.2 \mathrm{mil}-$ lion newborn circumcisions were performed in the United States. The estimated direct cost of these procedures was $\$ 1.2$ billion, a large sum of health care funds that could be directed toward more effective preventative and therapeutic interventions. ${ }^{6}$

\section{Prevention of HIV/AIDS}

A complete discussion of the relation of male circumcision and HIV is beyond the scope of this paper. Some studies conducted in Africa have shown that HIV is more common in uncircumcised males, while others have shown the opposite or no difference. Despite the fact that the evidence indicating a protective effect of circumcision is based on observational studies of adult circumcision in a developing country, there is now a ground swell of support for considering the procedure as a viable strategy for preventing sexually acquired infections. A recent Cochrane systematic review found insufficient evidence to support an interventional effect of male circumcision on HIV acquisition in heterosexual men. The authors noted that individual "researcher's personal biases and the dominant circumcision practices of their respective countries" complicated the interpretation of the existing data on the effect of circumcision on HIV transmission rates.7 Three randomized controlled trials (RCTs) have subsequently been published on heterosexual female- 
to-male transmission of HIV in high-risk areas of sub-Saharan Africa. ${ }^{8-11}$ All 3 supported adult circumcision as a protective measure. However, these trials were all terminated early, a characteristic that tends to overstate the effect of an intervention. In North America, where HIV rates are much lower, transmission is primarily by homosexual contact and intravenous drug use, making these RCTs inapplicable to this jurisdiction. Further, based on $1998 \mathrm{WHO}$ data of developed countries, the United States has the highest rate of HIV and also the highest rate of infant circumcision. ${ }^{5}$ This alone casts doubt on the utility of routine circumcision in preventing HIV infection in developed countries.

\section{Prevention of cervical carcinoma}

It has been observed that the prevalence of cervical cancer is low where male circumcision is practised. Historically, this has been attributed to a decreased prevalence of human papilloma virus (HPV) on the circumcised penis. However, a recent meta-analysis on HPV and circumcision concluded that the medical literature does not support the claim that circumcision reduces the risk of genital HPV infection. ${ }^{12}$ Even if circumcision conferred a reduction of HPV, does that indicate that routine circumcision should be advocated to reduce the prevalence of the vector for cervical cancer? The use of surgery for disease prevention is an unusual public health intervention. It would seem a more prudent health care policy to offer the recently available HPV vaccine against oncogenic strains of the virus to young females before the onset of sexual activity than to perform surgery on all males in the neonatal period. ${ }^{13}$

\section{Prevention of penile carcinoma}

Over the last 75 years, many case series showing that most penile cancers occurred in uncircumcised individuals have been published. Does that indicate that all males should be circumcised to prevent this rare cancer? It is notable that the incidences of penile cancer in Denmark, Finland, Norway and Japan, where less than $1.5 \%$ of men are circumcised, are lower than in the United States, where the majority of men are still circumcised. ${ }^{14-18}$ If circumcision is believed to decrease the risk of developing cancer, why do these noncircumcising countries with similar standards of living and hygiene have lower incidences of penile cancer?

The American Academy of Pediatrics policy notes that 9-10 cases of penile cancer are diagnosed each year per 1 million men, indicating that, although the risk is higher for uncircumcised men, the overall risk is extremely low. ${ }^{19}$ Because this disease is rare and occurs later in life, advocating circumcision as a preventive practice is difficult to justify.

\section{Prevention of future foreskin problems}

One of the difficulties in assessing the incidence of foreskin problems in the non-circumcised male is that of defining "phimosis." All newborn males have a physiologic phimosis, with the glans adherent to the inner mucosal surface of the prepuce. Gradual separation of the glans from prepuce takes place spontaneously over many years, often not being complete until puberty. ${ }^{20}$ Referrals for circumcision later in childhood because of an asymptomatic non-retractile foreskin, possibly with some ballooning upon voiding, are commonly made in error. Usually, in this setting, anxious parents and referring physicians require education on the care of the normal foreskin and the patient does not require an operation. ${ }^{21}$ The Canadian Pediatric Society states that no more than $1 \%$ of boys will require post-neonatal circumcision, and Australian reports indicate that normal preputial adhesions are often misdiagnosed as phimosis, leading to unnecessary circumcisions. $^{22,23}$ The rate of true pathological phimosis is less than $1 \%{ }^{24}$ and this usually responds to a short course of topical steroid ointment. ${ }^{25}$ Occasionally, uncircumcised boys experience an episode of balanitis requiring oral antibiotic therapy. The rate of this is estimated at $1 \%-2 \%$ and does not justify prophylactic or therapeutic circumcision. ${ }^{26}$ An analogous situation would be to recommend myringotomy and tubes in every child who suffers an episode of otitis media.

\section{Complications of newborn circumcision}

Health is not only about disease prevention, but also about well-being and the avoidance of harm. How harmful is routine non-therapeutic circumcision? The overall rate of immediate and longterm complications arising from newborn circum- 
cision is a matter of debate and in truth unknown. The estimated rate of complication worldwide has been reported as lying between the extremes of $0.1 \%$ and $35 \% .^{27}$ Minor complications such as bleeding, infection and prolonged hospitalization are thought to occur in less than $5 \%$ of cases. Tragic partial or complete penile amputation, urethral injury and even the rare death have been reported. Meatal stenosis requiring intervention occurs in $5 \%-10 \%$ of males circumcised in the newborn period. ${ }^{28}$ This is believed to be secondary to dermatitis of the unprotected glans exposed to wet diapers. Circumcision revision under anesthetic for penile concealment, skin bridges or an unacceptable cosmetic result is probably the most common long-term complication prompting a urological referral: in one survey, fully one-third of pediatric urologists in the United States reported experience as an expert witness in circumcision litigation cases..$^{29}$

\section{Conclusion}

Newborn circumcision remains an area of controversy. Social, cultural, aesthetic and religious pressures form the most common reasons for nontherapeutic circumcision. Although penile cancer and UTIs are reduced compared with uncircumcised males, the incidence of such illness is so low that circumcision cannot be justified as prophylaxis. The role of the foreskin in HIV transmission in developed countries is unclear, and safe sexual practice remains the cornerstone of prevention. There remains a lack of knowledge regarding what constitutes the normal foreskin both among parents and among primary care providers. This lack of knowledge results in a burden of costs to our health care system in the form of unnecessary urological referrals, expansion of wait times and circumcisions. Routine circumcision of all infants is not justified from a health or cost-benefit perspective.

Head, Division of Pediatric Urology, Department of Urological Sciences, University of British Columbia, Vancouver, BC

The positions provided in the Point / Counterpoint series are presented as general information and do not necessarily reflect the personal opinions of the authors.

This article has been peer reviewed.

Competing interests: None declared.

\section{References}

1. Dalton JD. Male circumcision - see the harm to get a balanced picture. JMGH 2007;4:312-7.

2. Schoen EJ. Circumcision as a lifetime vaccination with many benefits. JMHG 2007;4: 306-11.

3. Wiswell TE, Smith FR, Bass JW. Decreased incidence of urinary tract infections in circumcised male infants. Pediatrics 1985;75:901-3.

4. Chessare JB. Circumcision: is the risk of urinary tract infection really the pivotal issue? Clin Pediatr (Phila) 1992:31:100-4.

5. Van Howe RS. A Cost-utility analysis of neonatal circumcision. Med Decis Making 2004;24:584-601.

6. Hill G. The Case Against Circumcision. JMHG 2007;4:318-23.

7. Siegfried N, Muller M, Volmink J, et al. Male circumcision for prevention of heterosexual acquisition of HIV in men. Cochrane Database Syst Rev 2003; CD003362.

8. Denniston GC. Hill G. Male circumcision in HIV prevention. Lancet 2007;369:1598.

9. Bailey RC, Moses S, Parker C, et al. Male circumcision for HIV prevention in young men in Kisumu, Kenya: a randomized controlled trial. Lancet 2007;369:643-56.

10. Gray RH, Kigoze G, Serwadda D, et al. Male circumcision for HIV prevention in men in Rakai, Uganda: a randomised trial. Lancet 2007;369:657-66.

11. Auvert B, Taljaard D, Lagarde E, et al. Randomised controlled intervention trial of male circumcision for reduction of HIV infection risk: the ANRS 1265 trial. PLoS Med 2005;2:e298

12. Van Howe RS. Human papillomavirus and circumcision: A meta-analysis. J Infect 2007;54:490-6.

13. Rambout L, Hopkins L, Hutton B, et al. Prophylactic vaccination against human papilomavirus infection and disease in women: a systematic review of randomized controlled trials. CMAJ 2007; 177:469-79.

14. Frisch $M$, Friis $S$, Kruger-Kjaer $S$, et al. Falling incidence of penis cancer in an uncircumcised population (Denmark 1943-90). BMJ 1995;311:1471.

15. Iverson T, Tretti S, Johansen A, et al. Squamous cell carcinoma of the penis and of the cervix, vulva and vagina in spouses: is there any relationship? An epidemiological study from Norway, 1960-92. Br I Cancer 1997;76:658-60.

16. Maiche AG. Epidemiological aspects of cancer of the penis in Finland. Eur J Cancer Prev 1992;1:153-8.

17. Muir CS, Nectoux J. Epidemiology of cancer of the testis and penis. Natl Cancer Inst Monogr 1979;53:157-64.

18. Wingo PA, Tong T, Bolden S. Cancer statistics, 1995. CA Cancer I Clin 1995;45:8-30.

19. Hirii H, Charlton R, Sarmah S. Male circumcision: a review of the evidence. JMHG 2005;2:21-30.

20. Cold CJ, Taylor JR. The prepuce. BJU Int 1999;83(suppl 1):34-44.

21. McGregor TB, Pike JG, Leonard MP. Phimosis-A diagnostic dilemma? Can J Urol 2005;12:2598-602.

22. Canadian Paediatric Society. 2007. A:vailable: www.caringforkids.ca/babies /circumcision.htm (accessed 2007 Sept 20).

23. Spilsbury K, Semmens JB, Wisniewski ZS, et al. Circumcision for phimosis and other medical indications in Western Australian boys. Med J Aust 2003;178:155-8.

24. Shankar KR, Rickwood AM. The incidence of phimosis in boys. BJU Int 1999;84:101-2.

25. Ashfield JE, Nickel KR, Siemens DR, et al. Treatment of phimosis with topical steroids in 194 children. J Urol 2003;169:1106-8.

26. Escala JM, Rickwood AM. Balanitis. Br J Urol 1989;63:196-7.

27. Christakis DA, Harvey E, Zerr DM, et al. A trade-off analysis of routine newborn circumcision. Pediatrics 2000; 105:246-9.

28. Van Howe RS. Incidence of meatal stenosis following neonatal circumcision in a primary care setting. Clin Pediatr (Phila) 2006;45:49-54.

29. Gibson DM. Re: cost analysis of neonatal circumcision in a large health maintenance organization. J Urol 2006;175:2316-7.

Correspondence: Dr. A.E. MacNeily, KO-134 BC Childrens Hospital, 4480 Oak St., Vancouver BC V6H 3V4; amacneily@cw.bc.ca 


\section{Circumcision for all: the pro side}

\section{Anne-Marie Houle, MD, FRCSC, FAAP}

\section{The 8 best reasons for routine newborn male circumcision}

8. Circumcision decreases the risk of urinary tract infection.

7. Circumcision reduces the risk of heterosexually acquired HIV infection in men.

6. Circumcision lowers the risk of STDs.

5. Circumcision protects against penile cancer.

4. Circumcision reduces the risk of penile HPV infection and the risk of cervical cancer in female partners.

3. Circumcision prevents chlamydia infections and subsequent pelvic inflammatory disease, ectopic pregnancy and infertility.

2. Circumcision decreases the risk of balanoposthitis and phimosis and the later need for postneonatal circumcision.

1. Circumcision improves sexual function and creativity.

\section{Circumcision decreases the risk of urinary tract infection}

Since the first report by Wiswell and colleagues, a significant number of studies have confirmed the lower incidence of urinary tract infection (UTI) in circumcised, compared with uncircumcised, boys. ${ }^{1-4}$ The only matter of debate in this area is the magnitude of the circumcision protective effect. Depending on which author one reads, it could range from a 10-fold decreased risk to 3.7. One will argue that for circumcision to be cost effective the rate of UTI among infant boys would have to be equal to or above $29 \%,{ }^{5}$ which is far from the accepted rate of about $1 \% .{ }^{6}$ But one has to expand one's thinking further to be able to better analyze the impact of a UTI early in life. Indeed, it has been reported that as many as $10 \%$ of infants with UTI will have simultaneous bacteremia and $3 \%-5 \%$ of children will develop concurrent meningitis. ${ }^{7}$ Other severe acute complications of
UTI during infancy have been reported, including renal failure and death. ${ }^{8}$ Thus, for a small lifetime net cost estimated at US $\$ 17$, a circumcised male infant can expect an average 10-fold decrease in relative risk of UTI, including a 15 -fold reduction in relative risk of serious UTI requiring hospitalization, not to mention the decreased risk of severe concomitant complications. ${ }^{4}$ It is not so inconsequential after all to be able to reduce 10fold the risk of UTI early in life and its associated cost, even in the face of its low incidence!

\section{Circumcision reduces the risk of heterosex- ually acquired HIV infection in men}

Recently 3 independent trials have demonstrated that male circumcision reduces the risk of heterosexually acquired HIV infection in men by about $60 \%{ }^{9-11}$ This has prompted the WHO to recommend that male circumcision be part of a comprehensive HIV prevention package including the provision of HIV testing and counselling services, treatment of sexually transmitted diseases (STDs), promotion of safer sex habits, and the promotion of correct and consistent condom use. It seems evident that this would be effective in regions where the transmission is predominantly heterosexual, but what about regions where transmission is predominantly by mother to child, blood and blood products transfusions, use of contaminated syringes and needles, and homosexual contact? It may not be as obvious, but male circumcision may still play an indirect role in reducing HIV transmission. Indeed, if male circumcision results in an overall decrease in HIV infections, then women will ultimately benefit as it will consequently prevent male-female sexual transmission of the infection from men infected by other sources. ${ }^{12}$ Several mechanisms have been postulated to explain how the foreskin could increase the risk of HIV infection. These include poor foreskin hygiene, the propensity of the foreskin to ulcerative lesions or abrasions, and the presence of high concentrations of HIV target cells on the 
inner or mucosal surface of the foreskin, which is not protected by keratin, making it vulnerable to HIV infection. ${ }^{12}$

\section{Circumcision lowers the risk of STDs}

In 2006, a systematic review and meta-analysis confirmed that male circumcision provides a direct benefit in reducing the risk of STD as well as indirect protection against HIV by lowering STD prevalence. ${ }^{13}$ Thus, if male circumcision is promoted as an HIV prevention measure, an added benefit would be protection against ulcerative STD, both of which carry a significant public health burden. Considering that circumcision reduces the incidence of genital ulcer diseases and enhances penile hygiene and thereby protects both against HIV transmission and cutaneously acquired STD, it should be advocated as a public health measure along with the continued promotion of condom use.

\section{Circumcision protects against penile cancer}

The most important etiologic factor of penile cancer is thought to be the presence of an intact foreskin. ${ }^{14}$ Recently, in a study of a large populationbased sample of men, Schoen and colleagues demonstrated the highly protective effect of newborn circumcision on invasive penile cancer..$^{15}$ These results in turn confirmed the original findings of Wolbarst's study in 1932 and of 5 other major series since then, which showed in the 592 cases of penile cancer in the United States, that none of those afflicted were circumcised in infancy despite a high prevalence of newborn circumcision. ${ }^{16}$

\section{Circumcision reduces the risk of penile HPV infection and the risk of cervical cancer in female partners}

It has been shown that male circumcision is associated with a reduced risk of penile human papillomavirus (HPV) infection and, in cases of men with history of multiple sexual partners, a reduced risk of cervical cancer in their current female partners. ${ }^{17}$ The incidence of cervical cancer has been reported to be twice as high if the uncircumcised men are at low risk, but it increased to 5 times higher in men with 6 or more sexual partners. ${ }^{17}$ Even in a population in which circumcision is rare, being uncircumcised is one of the strongest risk factors for oncogenic and nononcogenic HPV infection. ${ }^{18}$ Even if one considers the use of surgery as an unusual public health intervention for prevention, one has to recognize its permanency, which is far from proven for the popular HPV vaccine. ${ }^{19,20}$ In fact, the benefits, particularly in terms of cervical cancer reduction, are thought to be highly dependent on the duration of vaccine protection for which evidence is currently limited. ${ }^{20,21}$ Moreover, the cost effectiveness of prophylactic HPV vaccines in Canada remains to be clearly demonstrated. ${ }^{22}$

\section{Circumcision prevents chlamydia infections and subsequent pelvic inflammatory disease, ectopic pregnancy and infertility}

Chlamydia is a major cause of pelvic inflammatory disease, ectopic pregnancy and infertility. It is the second most common STD, behind HPV infection. Chlamydia is recognized as a cofactor for the transmission of HIV and HPV owing to the local inflammatory state it induces. By preventing chlamydia infection, circumcision reduces the added cost of treating infertility by in vitro fertilization and the extra cost of dealing with ectopic pregnancy ${ }^{23}$ in addition to the protective effects against STD, HIV and penile cancer.

\section{Circumcision decreases the risk of balanoposthitis and phimosis and the later need for postneonatal circumcision}

On the basis of published studies, it is estimated that balanoposthitis and phimosis will develop in $3.5 \%$ of uncircumcised males. ${ }^{24}$ In addition, in Finland, where the rate of circumcision has been cited as low, it has been reported that about $7.1 \%$ of uncircumcised male infants will require circumcision later in life (M. Gissler, National Research and Development Center for Welfare and Health, written communication, February 2000). It is also generally accepted that postneonatal circumcision is not only more costly than newborn circumcision, ${ }^{25}$ but also that it carries an added risk attendant to the usually required general anesthesia and additional morbidity in the form of time lost from school or work. ${ }^{6}$ 


\section{Circumcision improves sexual function and creativity}

Laumann and colleagues, in 1997, demontrated that not only were uncircumcised men more prone to have sexual difficulties, compared with circumcised men, but also that circumcised men enjoyed a more elaborate sexual lifestyle and that their female partners were more pleased with the esthetics of the circumcised penis. ${ }^{26}$ In addition, Masters and Johnson have long established that there were no differences in glandular tactile stimulation between circumcised and uncircumcised men. ${ }^{27}$

Evidence is accumulating and a consensus is forming that neonatal circumcision offers nonnegligible lifetime health benefits by protecting against infant UTI and its associated, possibly severe, complications, HIV, ulcerative STD, and penile and cervical cancers. Complications to the procedure are rare and almost always minor..$^{8,28}$ Even from a cost analysis perspective, neonatal circumcision, once totally unthinkable, is gaining more attention and respect. ${ }^{4}$ Consequently, parents should always be given the most current and sound medical information regarding the benefits and risks of the procedure. One should remember, however, that one's decision is more greatly influenced by the circumcision status of the father, ethnic background and religion. ${ }^{29}$ Cost and health factors should then be removed from the decision and personal factors should be considered of primary importance when the procedure is discussed.

From the Department of Pediatric Urology, Université de Montréal, and the Mother and Child University Hospital Center, CHU Sainte-Justine, Montréal, Que.

The positions provided in the Point / Counterpoint series are presented as general information and do not necessarily reflect the personal opinions of the authors.

This article has been peer reviewed.

Competing interests: None declared.

\section{References}

1. Wiswell TE, Smith FR, Bass JW. Decreased incidence of urinary tract infections in circumcised male infants. Pediatrics 1985;75:901-3.

2. To T, Agha M, Dick PT, et al. Cohort study on circumcision of nemborn boys and subsequent risk of urinary tract infection. Lancet 1998;352:1813-6.

3. Schoen EJ, Colby CJ, Ray GT. Newborn circumcision decreases incidence and costs of urinary tract infections during the first year of life. Pediatrics 2000;105:789-93.

4. Schoen EJ, Colby CJ, Trinh TT. Cost analysis of neonatal circumcision in a large health maintenance organisation. J Urol 2006;175:1111-5.

5. Chessare JB. Circumcision: Is the risk of urinary tract infection really the pivotal issue? Clin Pediatr (Phila) 1992;31:100-4.

6. Task Force on Circumcision. Circumcision policy statement. Pediatrics 1999;103:686-93.

7. Bachur R, Caputo GL. Bacteremia and meningitis among infants with urinary tract infections. Pediatr Emerg Care 1995; 11:280-4.

8. Wiswell TE, Geschke DW. Risk from circumcision during the first month of life compared with those for uncircumcised boys. Pediatrics 1989;83:1011-5.

9. Auvert B, Taljaard D, Lagarde E, et al. Randomized controlled intervention trial of male circumcision for reduction of HIV infection risk: the ANRS 1265 trial. PLOS Med 2005;2:e298.

10. Bailey RC, Moses S, Parker C, et al. Male circumcision for HIV prevention in young men in Kisumu, Kenya: a randomized controlled trial. Lancet 2007;369:643-56.

11. Gray RH, Kigoze G, Serwadda D, et al. Male circumcision for HIV prevention in men in Rakai, Uganda: a randomised trial. Lancet 2007;369:657-66.

12. Vardi Y, Sadeghi-Nejad H, Pollack S, et al. Male circumcision and HIV prevention. J Sex Med 2007:4:838-43.

13. Weiss HA, Thomas SL, Munabi SK, et al. Male circumcision and risk of syphilis, chancroid, and genital herpes: a systematic review and meta-analysis. Sex Transm Infect 2006:82:100-10.

14. Bunker CB. Topics in penile dermatology. Clin Exp Dermatol 2001;26:469-79.

15. Schoen EJ, Oehrli M, Colby CJ, et al. The highly protective effect of newborn circumcision against invasive penile cancer. Pediatrics 2000;105:E36.

16. Schoen EJ. The relationship between circumcision and cancer of the penis. CA Cancer J Clin 1991;41:306-9.

17. Castellsagué X, Bosh FX, Muñoz N, et al. Male circumcision, penile human papillomavirus infection and cervical cancer in female partners. N Engl J Med 2002;346:1105-12.

18. Svare El, Kjaer SK, Worm AM, et al. Risk factors for genital HPV DNA in men resemble those found in women: a study of male attendees at a Danish STD clinic. Sex Transm Infect 2002;78:215-8.

19. Van de Velde N, Brisson M, Boily MC. Modeling human papillomavirus vaccine effectiveness: quantifying the impact of parameter uncertainty. Am J Epidemiol 2007; 165:762-75

20. Brisson $M$, Van de Velde N, De Wals $P$, et al. Estimating the number needed to vaccinate to prevent diseases and death related to human papillomavirus infection. CMAJ 2007; 177:464-8.

21. Rambout L, Hopkins L, Hutton B, et al. Prophylactic vaccination against human papillomavirus infection and disease in women: a systematic review of randomized controlled trials. CMAJ 2007;177:469-79.

22. Brisson $M$, Van de Velde N, De Wals $P$, et al. The potential cost effectiveness of prophylactic human papillomavirus vaccines in Canada. Vaccine 2007;25:5399-408.

23. Castellsagué $X$, Peeling RW, Francheschi $S$, et al. Chlamydia trachomatis infection in female partners of circumcised and uncircumcised adult men. Am J Epidemiol 2005; 162:907-16

24. Cameron DW, Simonsen JN, D'Costa $\downarrow$, et al. Female to male transmission of human immunodeficiency virus type 1: risk factors for seroconversion in men. Lancet 1989;2:403-7.

25. Circumcision and circumspection. Lancet Infect Dis 2007;7:303.

26. Laumann E0, Masi CM, Zuckerman EW. Circumcision in the United States. JAMA 1997;277:1052-7.

27. Masters WH, Johson VE. Human sexual response. Boston: Little Brown and Company; 1996. p. 189-91.

28. Christakis DA, Harvey E, Zerr DM, et al. A trade-off analysis of routine newborn circumcision. Pediatrics 2000; 105:246-9.

29. Binner SL, Mastrobattista JM, Day MC, et al. Effect of parental education on decision-making about neonatal circumcision. South Med J 2002;95:457-61.

Correspondence: Dr. A-M Houle, 3175 Côte-Sainte-Catherine, Montréal QC H3T 1C5; anne-marie_houle@ssss.gouv.qc.ca 


\section{Dr. MacNeily's Rebuttal}

$\mathrm{R}$ egarding UTIs, we are asked to support circumcision to reduce concerning and rare complications of an even rarer event without consideration of the cost and complications of the procedure. Health policies should be formulated on data, risk-benefit analyses and costbenefit ratios, not fear.

In our exploration of HIV and other STDs, many of the same references are quoted for both the pro and the con side of the debate, but we draw differing conclusions. This speaks to the complexity of the issue and the lack of definitive evidence. The logic supporting the application of data from adults in the developing world to endorse surgery on newborn children in the developed world remains weak at best. Prevention of STDs requires education and safe sexual practices, not surgery.

There is little argument that removal of the foreskin in early childhood all but prevents penile carcinoma. It is equally true that prepubertal castration prevents prostate carcinoma. Why not prophylactic tonsillectomy to prevent tonsillar cancer as well? The answer, in short, is that the number needed to treat is astronomical.
It is agreed that the cost effectiveness of the new HPV vaccine for prevention of cervical carcinoma remains to be proven. The same is true regarding newborn circumcision.

It is acknowledged that postneonatal circumcision is more costly and morbid. It is also a rare requirement. More education of primary care providers is required, not more surgery.

Finally, I am intrigued by the claims of "improvements in sexual function and creativity" brought about by circumcision. This evokes many images in the mind of the reader. However, one fails to see how the surgical removal of the end of one's penis leads to creative thinking!

Clearly there is one thing that we agree on in this debate, as summarized in both closing statements: cost and health factors are often ignored, and personal factors are usually of primary importance when this procedure is discussed with families.

The positions provided in the Point / Counterpoint series are presented as general information and do not necessarily reflect the personal opinions of the authors.

This article has been peer reviewed.

Competing interests: None declared.

\section{Change of address}

We require 6 to 8 weeks' notice to ensure uninterrupted service. Please send your current mailing label, new address and the effective date of change to:

\section{CUA}

1155 University Ave., Suite 1155

Montréal QC H3B 3A7

journal@cua.org 